\title{
Tribes, Territories and Networks in the Tourism Academy
}

\author{
Abstract \\ This article critically analyses the territories and tribes of tourism studies, an aim which \\ initially divides into two objectives. The first of these is an epistemological enquiry \\ which focuses on the nature and the structure of the field. The second objective is a \\ sociological one which focuses on the culture and practices of academics in the field. \\ However whilst this traditional distinction can bring some clarity to an initial \\ understanding of tourism studies, additional insights into the complexity and dynamics of \\ the field are obtained by adding a further layer of analysis. Here actor-network theory is \\ deployed to link relevant objects and reveal academic networks. Keywords: \\ epistemology, social science of knowledge, power, culture, actor-network theory.
}

\section{Introduction}

Tourism is an activity of undisputed significance in contemporary society and the extraordinary growth of the phenomenon has given rise to a concomitant growth in the tourism academy and tourism knowledge. But the canon is fragmented, the subject remains a somewhat Cinderella area in the academy and its academics range from management scientists and economists, through cultural geographers and anthropologists to sociologists. The pioneers who established the field are retiring, gradually superseded by a new generation of scholars so the field is at a crossroads in its development and therefore ripe for critical review.

The aim of this article, prompted by Becher and Trowler's (2001) enquiry into Academic Tribes and Territories, is to critically analyse tourism studies. This initially generates two objectives - an epistemological enquiry focussing on the nature and structure of the field and a sociological enquiry focussing on the culture and practices of academics. The outcome is a better understanding of the field and the effects of its rules, hierarchies and cultures. The article commences with the method section. The main body combines literature and findings discussing first the territories of the field and then its tribes. From this a third objective, an understanding of actor networks, emerged. Finally the conclusion critically reflects on new ways of understanding the field and reviews key findings.

\section{Method}

The method evolved over the course of this study. Central to it was a series of semistructured in-depth interviews and an open-ended email survey conducted with tourism academics (researchers, lecturers, managers). A sampling frame was used to ensure that respondents' attributes offered a range of locations, gender, academic seniority, disciplines, ethnicity and age. Academic seniority was defined as being a professor, department head, or holding a position of high peer esteem. Table 1 shows the basic characteristics of the sample and demonstrates balance over gender and academic seniority but still with some bias towards older, white respondents operating in developed countries. A comprehensive range of disciplines is represented including Economics, 
Geography, Sociology, Anthropology, Management and "Tourism”. Considerable effort was made to recruit outside of the Anglo/US/Australasian milieu of which the author is part and the sample includes those from South America, Canada, Africa, China, Europe, Israel and India.

Table 1: Sample

Crude Categories

Age

$\mathrm{n}=$

Gender

$\mathrm{n}=$

Status

$\mathrm{n}=$

Colour

$\mathrm{n}=$

Location

$\mathrm{n}=$

Sample, $N=67$

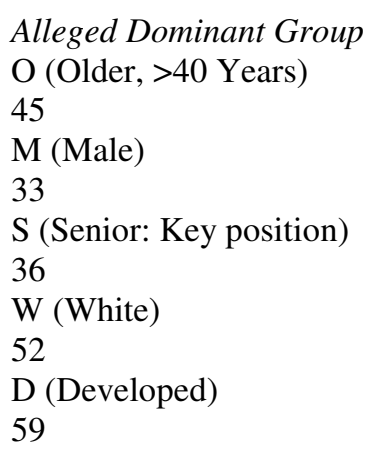

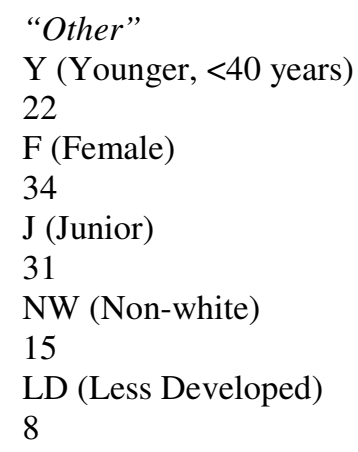

A qualitative approach satisfied the need to collect rich data and offer voice to the researched. The duration of the interviews (typically 60 to 90 minutes) was of sufficient length to allow complex issues to emerge. The interviews were face-to-face and enabled the researcher to deeply probe and analyse the complexities of the field. The questions and categories were inspired by those used in the Becher and Trowler (2001) study. They were adjusted in the light of a pilot study, mainly for clarity and to reduce excessive length and over-direction. For the final version, informants were provided in advance with a schedule of topics which guided the interviews and the following were of relevance to this article: Networks; structure of field; epistemological issues and power and hierarchies. The interviewer encouraged the introduction of relevant but unforeseen issues.

During data collection new sources of data emerged. The first was a series of reflections by nine academics in a chapter titled Processes of Becoming: Academic Journeys, Moments and Reflections (Ateljevic et al., 2007). The second was a set of thirteen autoethnographies (Nash, 2007) by senior academics in the sociology and anthropology of tourism. The arrival of these, along with the use of four other pre-exiting autobiographical accounts (Botterill, 2003; Hall, 2004; Ateljevic et al., 2005; Swain \& Hall, 2007) and an obituary (Airey, 2007) enabled data saturation to be achieved at an earlier stage than anticipated over some categories and so the interviews were rescheduled and questions edited in order to concentrate on under represented groups and under explored themes. They were also supplemented by an email version of the survey. The final sample size was determined by apparent data saturation at 67 subjects. This comprised of 16 interviews, 22 email surveys and 29 other biographical or autobiographical accounts. Additionally the researcher's long period of participant observation in the field was a source of data.

The interviews were recorded and transcribed verbatim. The method of analysis was data immersion with expert reading and re-reading against deep knowledge of the subject culminating in the clustering of data around key analytic headings. Tools such as $\mathrm{N}$ - 
VIVO were considered but the researcher was able to better and more imaginatively analyse complex data using deep and prolonged contemplation aided by manual memos and generating and manipulating categories using the outline/ headings feature in Microsoft Word. This resulted in three possibilities of accommodation, modification and extension of the a priori categories in the light of data collected as well as the recognition of anomalies. An initial 30,000 words was first reduced to 18,000 and progressively to 10,000 words whilst maintaining the essence of the data. Considerable space is devoted to the words of the informants in order to underline tourism studies as a human practice. In reproducing their comments each is given an anonymous number as well as their profile characteristics for which table 1 provides a key. Additionally book and page references are given where (auto)biographical accounts were sourced. The abbreviation "IV" stands for interviewer. Neither space nor time permitted analysis of different perceptions arising from age, gender etc. but this might be an interesting avenue to pursue in a future study.

Some limitations and caveats to the method should be noted. First the researcher is a senior academic and one interviewee noted that this might condition some responses. Second the researcher is positioned and embodied. Bracketing (Creswell, 1998) is often offered as a strategy for isolating such effects. Of course the researcher attempted to cultivate an open mind but is reflexively aware of the limits to this. Third whilst the sample attempts to be inclusive it does not purport to be representative. Hence what is offered is one exploratory account amongst a range of possible others, but one that is plausible and measured in terms of the data, that triangulates with a wider literature and that is transparent and qualified in terms of method.

\section{Academic Tribes, Territories and Networks}

An unreflexive view of tourism studies might be represented by what Barnes (2001, p. 524) calls "the traditional model" or "presentism" where a discipline is seen as the result of some inevitable and focussed progressive working out of the issues at hand. In this view things could only work out in one way and the patterning of a discipline is almost determined by the (uncontested) facts of the matter which are there to be discovered and put together in a particular way, i.e. the academic territory of tourism is an inevitable, objectively determined configuration. But a substantial literature has emerged which has sought to problematise the question of knowledge production. Prominent in these are Becher and Trowler (2001) who conducted a comprehensive study into the general nature of academic tribes and territories. To do this they concentrated on "the epistemological properties of knowledge formation [territories] .... [and] the social aspects of knowledge communities [tribes]" (p. 24). The first two parts of this section follow this division.

\section{Academic Territories}

Academic territory refers to the epistemological nature of the field and relevant here are the part of Becher and Trowler's study that highlighted disciplinarity, the content of the field (its canon), whether the field contains hard or soft knowledge (paradigm questions) and the mode of enquiry. Each of those aspects of academic territory is now investigated in turn. 


\section{Disciplinarity}

Tribe's (1997) analysis established criteria to settle the question of disciplinary status and concluded that tourism studies was unable to pass this test. Rather it was found to be a field, or more specifically, two fields of study, labelled TF1 (The Business of Tourism) and TF2 (Non-Business related Tourism). Knowledge creation occurred, according to Tribe, by multi-disciplinary, interdisciplinary and extra-disciplinary efforts. Here, extradisciplinary knowledge means that which is pulled from the complexity of the problem being studied rather than pushed from the prevailing disciplines. There was however no empirical evidence offered in support of this thesis, an omission that this article will address. In doing so it will also evaluate two later contributions to the literature. Coles et al. $(2009$, p. 87$)$ conceptualise tourism more as a post-disciplinary area of study which "allows scholars to free themselves from the intellectual shackles applied by disciplinary policing ... encourag[ing] the valorization of knowledge produced elsewhere." Similarly, Hannam (2009) suggests the replacement of tourism studies by nomadology and the mobilities paradigm. Nomadology describes an even more radical deterritoralisation of the academic where as Deleuze and Guattari $(1988$, p.52) note "the nomad has no point, paths or land".

The almost unanimous describing of tourism as a field rather than a discipline by the informants provides compelling empirical evidence to support Tribe's (1997) "indiscipline" thesis: \#26 Y/F/J/NW/D: Tourism Studies is a field. It is still fragmented. \#23 Y/F/J/W/D: It is a field of study for different disciplines. I see just partial cohesion.

Similarly, Tribe's conceptualisation of two sub-fields (although not identified as TF1 and

TF2) and evidence of considerable fragmentation found widespread support: \#11 Y/M/J/W/LD: It's fragmented because the management is studied, about his perspective and the philosophy too, and the social scientist too.

\#20 Y/F/J/NW/D: Tourism studies to me is a field ... [dominated by] mainly economics, business management, and to some extent sociology and geography \#56 O/F/S/W/D: [two] fields, the business-driven and cultural critique-driven

And, like Tribe, some informants saw benefits in its lack of disciplinarity: \#8 O/M/S/W/D: ... it's a field but one of the things that I like about it is that people bring disciplinary issues with them to the study of Tourism ... so that we do have a wonderful collection of diverse ways of attacking questions or problems coming in from various existing fields.

There was one contrary view and one caveat expressed:

\#13 Y/F/J/W/D: ... because it gets much more volume, much more attention in the academic world, in universities, and I think it might be viewed more as a discipline than as a research field.

\#11 Y/M/J/W/LD: I think it's a field. But ... it can change to be a discipline.

It is interesting to note that none of the informants used the terms post-disciplinary or nomadology during the course of the interviews although one informant talked of the emergence of mobilities.

\section{The Canon}

The extent of recorded knowledge about a subject is known as the canon and one informant suggests that the canon of tourism studies is quite fully formed. 
\#37 O/F/S/W/D: Thirty years (1974-2004) of concentrated analysis ... have generated a vast body of data, theories, methodologies, and so-called best practices, which suggests that the basics of tourism have been largely identified and described (Nash, 2007, p. 196).

But the main argument used by Tribe to assert his "indiscipline" claim was the lack of tourism theory. Again, many of the informants supported this view:

\#63 O/M/S/W/D: It easily blurs into other areas; no unique jargon, language or theories other than in a superficial sense.

\#60 O/F/J/NW/D: ... it borrows, as it should, concepts and terminology from established disciplines and discourses. Examples are terms such as carrying capacity, sustainable development $\ldots$ tourist-gaze...

\#38 O/M/S/W/D: ... there aren't really any tourism theories - maybe TALC comes near, but that's not really unique to tourism.

\#56 O/F/S/W/D: ... As for unique theories, I do not think it has them ...

But a number of informants were able to identify some key and distinctive characteristics, e.g:

\#23 Y/F/J/W/D: Archer (demand forecasting); Cohen (sociology of tourism); Christaller (tourism location); Leiper (ditto); Butler (life cycle); Plog (psychographics in tourism); Gunn (planning); Ritchie and Crouch and Dwyer (competitiveness); Pearce (environment and tourism development); Poon (new tourism); Crompton (destination choice); Tourism and ICTs studies; pull and push factors approaches ...

\#61 Y/F/J/NW/D: in tourism we may talk of performativity, the gaze, embodiment, host/guest, 'other' which have their roots in other disciplines but we are making them our own in different ways.

\#21 O/F/S/W/D Yes, it does have its own jargon ... For example, those relating to tourist typologies etc. The same is true of theories - yes we do have some of our own.

So some informants can see tourism theory whilst others cannot. Barnes (2001, p. 527) offers a way to understand this apparent paradox. He explains how "theoretical change proceeds through a process of what [the Edinburgh school] call finitism ... [where] new theories typically stem from extending existing concepts in one field to new circumstances." This idea is neatly captured by two informants who note that: \#55 Y/F/J/W/D: ... tourism studies borrow[s] theories and concepts from other fields, but when tossed into the tourism studies cauldron, these ideas can yield something different and distinctive...

\#23 Y/F/J/W/D: ... tourism ... is a field of study, meaning that it mainly applies theories/methodologies and languages of other disciplines in producing knowledge. However it is in a transition phase: from 'simple' application of borrowed theories ... towards an understanding of specific factors making 'general' theories not sufficient (I think we are here) ... leading to a need of some unique theories/methodologies.

Indeed this confirms the point made by Tribe $(1997$, p. 643) who argued that: tourism studies can, in fact parade a number of concepts ... for example ... the tourism multiplier ... [but] ... they are concepts that have started life elsewhere and have been stretched or contextualised to give them a tourism dimension.

The process of finitism in tourism studies is likely to continue with the field embracing and adapting theories from its contributory disciplines and neighbouring fields since the boundaries of tourism studies are made of porous rather than solid membranes.

\section{Paradigms}

Becher and Trowler used the terms hard vs. soft knowledge (Biglan, 1973) where the former refers to the existence of a paradigm. For Kuhn (1962) a paradigm is set of rules 
that govern what is to be researched and how this should be conducted and presented. So the existence of a paradigm could lead to the suppression and exclusion of new knowledge. Overall the informants reject the notion of $a$ governing paradigm pointing to tourism studies as "soft" knowledge:

\#2 O/F/S/W/D: I actually don't feel that there is [a paradigm] ... There are people who have taken tourism in a certain direction, but I don't feel it's too restrictive. I think it's emerged in a bit of a free form, sort of way...

\#1 O/M/S/W/D: You could interchangeably ask tradition, paradigm, ideology, discourse - for me there's not one.

\#23 Y/F/J/W/D: There is not a paradigm, maybe because paradigms tend to be more present in 'mature' sciences ... Tourism is too young and the fact that it is connected to different disciplines may make it more difficult to arrive to a paradigm.

Some informants identified competing perspectives and there was disagreement about which was dominant. Some found positivism / managerialism dominant:

\#63 O/M/S/W/D: The curriculum and programmes have developed from a managerial/positivist position and these still tend to have a dominant position.

\#51 O/M/J/NW/LD: ... the field is still very much dominated by positivist/post-positivist paradigms, although the call for (or voice of) constructivist/interpretivist perspectives is getting louder ...

\#3 Y/M/J/W/D: It is very much a business related ... very quantitative, very numbers driven.

Still others found that positivism / managerialism was being squeezed out:

\#63 O/M/S/W/D: The research is no longer dominated by managerialism and positivism, indeed it may have turned its back too vehemently against these approaches.

\#49 O/M/S/W/D: ... tourism as an industry or from a positive business development perspective seems to get less exposure ...

This apparent paradox may be explained by the situatedness, or discursive networks of the informant: \#56 O/F/S/W/D: It depends what field you work in, what seems to be the dominant discourse. It is difficult even to picture it as "one field", due to the different discourses people speak when speaking of tourism.

The strength of the Foucauldian (1971) idea of discourse is illustrated by the struggles of informant 12 against what is seen as a prevalent (taken for granted) discourse: \#12 Y/F/J/W/D: ... when I talk to my department ... about issues of gender I'm automatically labelled as a feminist ... When he talks about any general topic, he actually talks about it from a very masculine point of view ... He actually talks about colonial man travelling the world and whatever but he just presents this as a part of travel history. So, his discourse is normalised, mine is not.

Some informants looked beyond the "rules" of the field pointing to the Gramscian notion of ideology to identify a broader, societal disciplining effect at work:

\#12 Y/F/J/W/D .... the dominant ideology is a neo-liberal business ideology ...

\#55 Y/F/J/W/D: Scientism, capitalism, neo-liberalism, materialism, individualism. These aren't the only ideas out there, but they're the hegemonic ones.

The idea of a fluid field, mobility of knowledge and an emerging paradigm of mobilities was introduced by one informant:

\#61 Y/F/J/NW/D: The wonderful thing about tourism is that it is in a constant state of movement ... I would say at the moment the dominant paradigms emerging are the mobilities paradigm, the shift towards critical and cultural thinking. 
In summary the idea of a paradigm is not supported by the informants. Rather their evidence points to a soft, permeable field comprised of different traditions (MacIntyre, 1985) which, unlike a paradigm-ruled field, can coexist and are susceptible to new schools of thought.

\section{Mode}

Becher and Trowler also studied the distinction between pure and applied knowledge. Pure knowledge is highly abstract whereas applied knowledge is closely aligned with real world problem solving. This division is related to the distinction between different modes of knowledge - mode 1 being that which is generated from within the academy and mode 2 being that which is extradisciplinary and arising from and focussed on applied contexts (Gibbons et al., 1994). Despite the apparent "real world" focus of the field a number of informants pointed to limited evidence of applied research:

\#66 Y/M/J/W/D: [What is overlooked is] real change through engagement with industry. I think we have got too set in our own ways and comfort zone.... My intention is to change industry practice ... using academic rigour to do so.

\#25 Y/F/J/NW/D: I also think many academics tend to concentrate on the "philosophy" instead of more actively seeking solutions, i.e. not very pragmatic.

\#46 O/F/J/W/D: I do question who reads [tourism] journal articles and what, other than for promotion, is the point in publishing in this forum (Ateljevic et al., 2007, p. 397).

\section{Academics Tribes}

An analysis of academic tribes in tourism focuses on the cultural practices of academics and the social construction of knowledge. This section uses the work of Merton's (1973) sociology of science, Becher and Trowler (2001), Barnes' (2001) analysis of economic geography, and Tribe (2006, p. 376) who noted that:

the canon of knowledge is heavily contingent on the power of those who speak for tourism, their spatial and temporal situatedness and the social practices that sustain their position and authority.

Barnes (2001) notes how Merton's (1973) concept of Institutionalism challenged the notion of disinterested knowledge by analysing the social side of knowledge creation and investigating the induction of scientists into their disciplines. Institutionalism describes the processes by which norms are set out for new areas of study especially in terms of what is to be studied, how it is to be studied and indeed who is to be central to studying it. This section investigates the institutions of universities and how these and other factors affect academic freedom. It then considers how cultural aspects (specifically clans and elders) and wider societal cultural values act upon tourism knowledge.

\section{Universities and Departments}

Academics cluster in formal academic groupings and are institutionalised within departments in universities. Tribe (2006, p. 371-372) used the term ' departmentalism', to describe the organisational effects of universities on research noting that "these structures have immense power to direct time, supply funds and corral research to fit a particular faculty strategy."

Being situated in a university can be a source of intellectual stimulation and freedom: 
\#36 O/M/S/W/D: [I] started studying $\ldots$ at the newly opened University of Vincennes, where so many of the most famous intellectual luminaries of the time were teaching-such as Foucault, Deleuze, Lyotard, and Bourdieu ... (Nash, 2007, p. 167-168).

But many informants are conscious of institutional socialisation:

\#40 Y/M/J/W/D: We learnt and played this new fangled game ... (Ateljevic et al., 2007, p. 388).

And others recognized departments as places to be carefully negotiated:

\#50 O/M/S/W/D: My encounters with the excesses of empirical realist (bean counting) accounts of social science occurred at Texas A and M University (Botterill, 2003, p. 100).

\#35 O/M/S/W/D: [I found myself] in the middle of the fight between combatants, which involved those (mostly Marxists) increasingly radicalized by the Vietnam war, and the biologically oriented wing of the department and their associates. ... I took sparingly from the Marxist view of things and struggled to remain autonomous ... (Nash, 2007, p. 156,157).

Many informants discuss the influence of departments:

\#67 O/M/S/W/D: the discourse varies substantially depending upon where the program/faculty member is housed. In the US, the primary focus is the "business of tourism;" however, many faculty in geography, sociology and anthropology that study tourism focus on a variety of issues not directly related to the industry of tourism.

\#2 O/F/S/W/D: if you're in a business school the way that you're thinking is much more business oriented.

\#28 O/M/S/W/D: Parsonian structural functionalism ... dominated the theoretical approach in the Department at the time ... [which was] under the sway of a few eminent scholars ... There was a general sense among the younger staff that their professional future depended upon close collaboration with their seniors ... This engendered a considerable degree of dependency, stifling to some extent the quest for an independent choice of topics (Nash, 2007, p. 52-53).

And sometimes there can be an explicit agenda for fitting in:

\#28 O/M/S/W/D: ... their seniors ... directed them toward specific research topics (Nash, 2007, p. 53).

\#7 Y/F/J/NW/D: in my university ... they're saying these are the streams that we're going to be supporting for research. And obviously business and management is one of the streams. So, if you're not necessarily doing anything that is business or management related, you really have to fight to make a strong case to get any sort of support for it, because it's not within the remit.

Fitting in presented difficulties for some:

\#52 Y/F/J/W/D: I felt often alone as a qualitative, gender-based researcher in a discipline where objectivity, generalisation and distance were the norm. I understood the tenets of scientific objectivity and quantitative research, as this was the paradigm which influenced my undergraduate studies, and struggled to justify to myself and others how I could adequately do a qualitative $\mathrm{PhD}$ (Ateljevic et al., 2005, p. 15).

\#43 O/F/J/W/D: Initially when confronted with such challenges from those that appeared not to understand and/or have sympathies with my particular perspective or world view, it was easier to retreat and sit in the shadows hoping that no one would notice what I was doing (Ateljevic et al., 2007, p. 392).

The informants are painting a mixed picture here - there is much talk about institutional socialisation, sometimes implicit, sometimes explicit with some struggling against departmental norms. This opens up an interesting area of research freedom which is investigated in the next section.

\section{Freedom to Research}

A number of informants viewed themselves as free agents in research: 
\#11 Y/M/J/W/LD: $\quad$.. we don't have limits. Each person can investigate whatever he likes.

\#38 O/M/S/W/D: ... free to research what I want.

\#8 O/M/S/W/D: I've never felt any constraint

\#23 Y/F/J/W/D: Free.

One informant explained that tourism studies offers liberation from the 'tyranny of the disciplines' (Aronowitz \& Giroux, 1991) where disciplines can impose restraining rules on how to conduct research:

\#35 O/M/S/W/D: I have found something like a home in tourism studies and a good deal of freedom ... which comes from being at a distance from disciplinary mainstreams (Nash, 2007, p. 165-166).

Informant 67 demonstrates a critically reflexive view of freedom pointing to cultural "baggage" and self-surveillance (Foucault, 1980) as constraints:

\#67 O/M/S/W/D: I am pretty much able to define what I see as important within the context of tourism. However, I am not certain what "free" means. I have the "baggage" of the way I see the world, my perceptions of responsibilities to the university, my students and more generally to the field.

Self-surveillance (as opposed to external coercion) can limit absolute freedom where academic actors avoid certain radical moves that might take them outside of a broad script that is officially (both implicitly and explicitly) legitimized.

Funding is a major constraint. "No money, no proof" according to Lyotard (1984, p. 45) who proposes the term performativity to describe the influence of research funding on truth, explaining that "... whoever is wealthiest has the best chance of being right". Many informants report funding agencies influencing which truth areas are investigated: \#60 O/F/J/NW/D: ... more than ever before, universities are funding industry oriented research.

\#21 O/F/S/W/D: My research is heavily influenced by whatever contract research I am engaged with, research council bids.

\#34 Y/F/J/W/D: ... the majority of tourism research is performative.

\#55 Y/F/J/W/D: ... the tourism cannon is unbalanced in favor of research that is marketable.

The Sustainable Tourism Co-operative Research Centre in Australia (STCRC) is quoted as an example of this:

\#3 Y/M/J/W/D: The research agenda I would like to follow was dictated pretty heavily by the CRC tourism.

\#2 O/F/S/W/D: In Australia ... the CRC has taken the view of consulting with industry and then setting a research agenda based upon industry rather than upon the researchers.

One informant directly stated that funding and publishing regimes constrained her research agenda:

\#7 Y/F/J/NW/D: ... because of the sort of constraints of who is going to fund this kind of work and where am I going to get it published, then I think that that is a constraint on the things that I sometimes do.

Lyotard (1984, p. 46) noted that in some cases "scientists, technicians and instruments are purchased not to find truth but to augment power". On informant found himself embroiled in this kind of truth selectivity:

\#66 Y/M/J/W/D: ... funding sources that want to promote positive messages have constrained what I say or publish.

But unlike say nuclear physics, much tourism research is cheap and this enables some researchers to maintain independent agendas: 
\#29 O/M/S/W/D: My twenty-year contribution to the anthropology of tourism has been based on a grand total of only $\$ 800$ in research funding (Nash, 2007, p. 72).

\#55 Y/F/J/W/D: My work is pretty low-cost ... so I'm able to keep it going despite not having an external source of funding.

\#54 Y/F/J/NW/D: ... what most people do is continue the work that is near and dear to their hearts while developing a similar, 'sexier' more marketable line of research from which they can successful obtain funding.

A second major issue that was raised as a constraining issue on research freedom was the need to publish in certain journals:

\#26 Y/F/J/NW/D: ... if you want to be promoted, then your research interests might be constrained due to publication requests from your employers.

\#64 O/F/J/W/D: ... the emphasis is strongly on publishing in the top-tier journals.

\#20 Y/F/J/NW/D: ... many academic journals define their boundaries and it only seems appropriate to research within those boundaries...

Finally it appears that older, well-established researchers have more freedom as evidenced by the different perspectives of informants 40 (younger) and 8 (older):

\#40 Y/M/J/W/D: ... I realised that academia, for all its promise of unbounded exploration, is an act of joining the dots, playing the game ... (Ateljevic et al., 2007, p. 387)

\#8 O/M/S/W/D: if you know that somebody's going to be looking at the quality of the journal that you're publishing in, you have to put a couple of articles in one of those journals. But, once you've done that ... then it's much more fun to publish in a place where there is innovation, good ideas, things happening ...

\section{Clans}

A useful insight into academic culture is provided by Crane (1972) who identified the operation of 'invisible colleges'. These include the meetings and associations where key academic groups cultivate their tribal territories but whose operation might not be transparent to everyone who operates in the field. There are many meetings and associations in tourism but one which bears some investigation is the International Academy for the Study of Tourism (IAST) often referred to as "The Academy". It is certainly invisible to many:

IV: Have you heard about The Academy of Tourism?

\#6 Y/F/J/NW/D: No.

\#13 Y/F/J/W/D: No.

\#2 O/F/S/W/D: Not really, no.

\#3 Y/M/J/W/D: Very vaguely ... That seems to be an elite. I am not quite sure what they do, I am not sure what kind of role that they play.

Indeed its lack of transparency leads one informant to talk about it secret society terms: \#7 Y/F/J/NW/D: It's just like there is this elite group of people who belong to this Academy ... Who are these people and how do you get on it? Is this by invitation only? What does it do? ... ... it's a secret society ... you don't know what goes on in it. You don't know how to get in there. So, that's why I say it's like a lodge.

The literature suggests that The Academy might exert a role in normalising (Kuhn, 1962) tourism studies and legitimising certain parts of the canon:

\#16 O/M/S/W/D: ... there is a clique ... in the academy - there's a group there that filled many of the editorial boards ... So I think there is a group that has substantial influence on the way the field unfolds. 
\#9 O/F/J/W/D: I see The Academy as a group of old guys ... There are about five or six women and about 77 members. ... They think they have a lot of influence. I think they do have a fair amount of influence in terms of having been gatekeepers to journals, etc.

\#12 Y/F/J/W/D: [The Academy] was apparently quite an elitist society ... and it is invitationonly based and it definitely comes from that old guard which ... wanted to give this scientific status to the Academy.

And invisible colleges can be a force for knowledge conservatism:

\#15 O/F/S/W/D: ...it is important to be aware of how the power structures work and how they exercise as well. And my concern in that regard would be that it perhaps inhibits new thinking, creative ways of writing...

Of course conservatism can sometimes lead to ossification:

\#1 O/M/S/W/D: ... look at the last two academy meetings; it's two years and they haven't produced the book from The Academy meeting yet. So that ability to transmit that information to people is really lost.

\#5 O/M/S/W/D: [Professor Z] has been staying with us the last week, and he's been talking about the Tourism Academy and saying, well, what a waste of space.

There was some discussion about the gender and ethnic balance of The Academy: \#16 O/M/S/W/D: ... it really struck me as an old boys' club and I think that's problematic. \#17 Y/F/J/W/D: ... clearly there's a very strong Anglo-Saxon male bias.

\#15 O/F/S/W/D: It's less than ten women ... Ethnically, it's pretty Caucasian.

It appears that there are signs of change in The Academy:

\#16 O/M/S/W/D: ... it seems that it has broadened and it has embraced newer people in more recent times ... Over the last handful of years it seems to have ... changed. \#9 O/F/J/W/D: [its influence] is being challenged and is changing, I think.

And the maleness of invisible colleges such as The Academy has generated resistance (Foucault, 1980) with female academics creating their own colleges such as SWIG: IV: Which [academic associations] do you belong to?

\#9 O/F/J/W/D: ... I belong ... to SWIG, the Society for Women Geographers ...

\section{Elders}

Academic esteem can arise from objective measures such as citation counts (McKercher, 2008) but a social line also marks off the "elders" of the tribes so that a distinction can be made between an old and new guard. Barnes (2001) points out how hierarchical positions in the academy can result from the 'cumulative effects' of being a subject pioneer and from the 'halo effect' of affiliation to elite institutions. Informant 13 alludes to this pioneer effect:

\#13 Y/F/J/W/D: ... if you are looking at old school tourism researchers, you could obviously put Cohen, Urry, Butler all in the same group ... it probably has some power from it being older, but if you think about it, it's the people who might be the pioneers of tourism researchers. I think they're like the guardian angels of tourism.

For some the old guard is also 'the old boys' club':

\#61 Y/F/J/NW/D: ... Old guard remain in place in business-focused tourism research ... certainly still legacies of the 'old boy's club'.

Following Kuhn (1962) we might surmise that the old guard could be resistant to change: \#21 O/F/S/W/D: Yes, I think there is [an old guard] ... One consequence may be that things are slow to change ...

\#3 Y/M/J/W/D: I think what is frustrating is there is a lot of the same people on every editorial board. There is no other new guard on those whatsoever ...

Informant 18 alludes to the power of patronage of the old guard: 
\#18 O/F/J/NW/D: In India ... the old guard continues to exert its influence on the new guard, most of who need them for sustenance.

In China a clear division of old and new guard was drawn:

$\# 10 \mathrm{O} / \mathrm{M} / \mathrm{S} / \mathrm{NW} / \mathrm{LD}$ : ... for the old professors they may study tourism studies $\ldots$ from Political Economics and these kind of things, but some youngsters they might be graduated or training in foreign countries ... and now there's more and more coming back to be members of the faculty which tries to do things, new things. This kind of time they have two layers of the professors or the academics. Young ones and the old traditional ones.

But criticism of the old guard was matched by praise:

\#59 O/F/S/W/D: ... experiences of 'old guard' very positive in that I have found many to be extremely helpful, generous and forthcoming ...

\#61 Y/F/J/NW/D: I have not experienced obvious inequality of access ...

There was also an observation which linked cognitive to the social:

\#54 Y/F/J/NW/D: Perhaps the fact that it is field (numerous in-roads) as opposed to a discipline (one way highway) reduces the hegemonic influence of the old guard.

The new guard are seen as a sign of fresh blood, optimism and many were keen to associate themselves with this term:

\#34 Y/F/J/W/D: There is certainly a new and old guard mentality and I definitely belong to the 'new guard'.

\#60 O/F/J/NW/D: ... a vibrant new-guard ... [is] taking over, a very healthy and encouraging sign.

\#54 $\mathrm{Y} / \mathrm{F} / \mathrm{J} / \mathrm{NW} / \mathrm{D} \ldots$ as more scholars have been inducted into the field, bringing with them novel approaches, the old boys club is slowly being rendered obsolete.

But some concern was raised about the new guard and what Pearce (2005) termed "generation T" (tourism, rather traditional discipline-based, graduates):

\#2 O/F/S/W/D: I feel the field is still a little bit weak. I think part of it is the whole issue that Phil Pearce just called it a new generation $\mathrm{T}$ and I tend to agree a little bit with that.

\#15 O/F/S/W/D ... Old guard to me, the tradition is a little more rigid, but they do bring the strong disciplinary background. The new guard and the new guard behind us, I'm worried that we're going to be watered down into the tourism people, hospitality people.

\#16 O/M/S/W/D ... with the newer people coming through, it's not a tie to a traditional discipline in many cases ... and I think that's a real problem.

\section{Wider Cultural Aspects}

It is not just the immediate academic culture that impinges upon the practices of academics but also the wider cultural milieu in which they work. Here the cultural studies of science literature provides pointers for analysis of issues such as gender, race, class, values and geographical location. Donna Haraway underlined the importance of these issues by coining the expression 'the gaze from nowhere' (Haraway, 1991, p. 188), which she used to critique the assumed objectivity of science. Knowledge rather emanates from somewhere, from someone, from embodied researchers who carry with them acquired cultural blueprints for action. These are not identical across researchers so researchers in different cultures may be interested in and produce different knowledge. The effects of this are neatly summarised by Barnes (2001, p. 540):

science is embedded within complex sets of social relations that variously shape its institutional form, rationale, practice, and knowledge. Because such social relations are always specific to a local context ... science studies argues that science [is] always relative to the geographical and historical context in which it takes place.

Tribe (2006, p. 375) echoed this theme noting that, 
tourism research carries with it a subtle power to define: to skew: to objectify: to foreground some issues leaving others untouched.

In relation to this, informants identified under-researched areas pointing to four key "silences". The most discussed was that of "other knowledges" which appear to be overlooked because of a culture of ethnocentrism:

\#12 Y/F/J/W/D: It's definitely issues of other knowledge, knowledge that's coming from other cultures [that is overlooked].

\#18 O/F/J/NW/D: Tourism studies is ... guided largely by occidental perceptions and philosophies. Few scholarly works from the oriental mindsets are known / available.

\#5 O/M/S/W/D: We haven't really talked at all about indigenous knowledge or indigenous science, if such a thing exists.

But there was also talk of resistance (Foucault, 1980) to this:

\#9 O/F/J/W/D: ... you, of course, are also so totally colonised by western perspective and yet there's a fair amount of influential resistance to that and a desire to more indigenised thinking from the cultural perspective. So I think there's hope for a multi-cultural tourism culture.

The second area where a thinness of research was reported was that of under-empowered groups, particularly the situation of minorities:

\#26 Y/F/J/NW/D: ... less developed countries; females; disabled people [are overlooked].

\#54 Y/F/J/NW/D: Unabashedly, I'll say that we have yet to award sufficient attention to issues of race and ethnicity.

\#6 Y/F/J/NW/D: ... not much on obviously ethnic minorities ... Not just ethnic minorities, any kind of small social groups for example.

\#12 Y/F/J/W/D: The different issues of woman empowerment, generally empowerment of all marginalised groups ...

The third area that was identified was that of power and politics:

\#7 Y/F/J/NW/D: I don't think that the sort of politics of tourism is as much focused on as it should be, and when I talk about politics I'm talking about issues of power.

\#1 O/M/S/W/D: The big business end of decision making in tourism, which is enormously powerful ... but we don't really study them ... Similarly, we don't study the very rich.

\#56 O/F/S/W/D: I would say social politics and policy, and work and labour, are underresearched.

Fourth, quality of life and the more spiritual, humanistic side of tourism was seen as a lacuna:

\#55 Y/F/J/W/D: There is far too little research on how tourism contributes to the world's problems and how it could better be used serve the public good and to increase quality of life for people who are currently underprivileged.

\#15 O/F/S/W/D: The whole, the almost spiritual content of what tourism can be, the transformational aspect of what tourism can be, is understated because it's not scientific. So ... the huge power that tourism has to change humanity that we haven't tapped into yet ...

\#12 Y/F/J/W/D: ... looking at tourism as a form of regional development that can potentially lead to that harmony between nature, economy and quality of life.

Finally for some academics the canon was complete and comprehensive (but it is interesting to note the profiles of both of these respondents):

$\# 63$ O/M/S/W/D: I am not sure that anything fundamental now is overlooked.

\#38 O/M/S/W/D: I can't think of anything that is overlooked. 


\section{Academic Networks}

Whilst the division between tribes and territories provides for analytical clarity, in reality there is much blurring and interconnectedness of tribes and territories. With this in mind this third section turns to actor-network theory (ANT) to uncover novel relationships circulating between tribes and territories and provide a new understanding of the field, especially the process by which it is constantly reconfigured. Using ANT, tourism studies is conceptualized and analyzed in terms of actors and a series of overlapping networks that are in constant flux - circulating, becoming, dissolving, merging and demerging. According to Law (1999, p. 3) "entities take their form and acquire their attributes as a result of their relationships with other entities." It is possible therefore to see an academic knowledge area as a series of networks (Barnes, 2001) which consist of entities that are related to one another. Meaning for these entities is produced by relations with other entities in the network each of which in ANT is referred to as an actor.

A number of aspects of ANT can be used to understand the working of knowledge areas. First ANT takes us beyond the social in that it encompasses non-human as well as human influences (the ANT principle of symmetry). In a tourism studies network these might include material and non-material entities including books, technologies and institutions. This broadening of scope is important and Latour (2005, p. 72) explains how not only humans but also things as actors "might authorize, allow, afford, encourage, permit, suggest, influence, block, render possible, forbid and so on."

Second, after Callon (2001, p. 64), tourism studies can be viewed as something that "must be composed, made up, constituted, established, maintained and assembled" and ANT has developed a number of concepts to explain the construction, extension and perpetuation of networks. 'Problematisation' is the articulation of the problem, or group of problems, that needs to be worked on and an initial scoping of the network and relevant actors. 'Interessement' is the process of mobilising the interest of actors and negotiating the basis of their involvement in networks. Actors who perform organising roles are termed 'primary actors'. Primary actors may establish themselves as 'obligatory passage points' that intermediate between actors and networks or provide essential points of reference. 'Enrolment' to a network occurs when actors assume the roles that have been negotiated with them during interessement. "'Translation' involves creating convergences and homologies by relating things that were previously different" (Callon, 1980 , p. 211) and therefore identifies new entities and relations. 'Inscription' is the way in which for example translations are "embodied in texts, machines, bodily skills [and these] become their support, their more or less faithful executive" (Callon, 1991, p. 143). Law (1992, p. 387) points out the importance of durable inscriptions so that "a relatively stable network is one embodied in and performed by a range of durable materials".

\section{Network Formation}

Airey (2005) traces the roots of tourism studies as far back as Rae (1891) but notes that early forays into the subject are relatively fragmented. This section illustrates the important process of consolidation and growth through network formation by reference to the development of two exemplar established networks (tourism social science and the business of tourism) and the emergence of a new network (critical tourism). It was the 
American Anthropological Association [AAA] that provided an existing network from which a significant network in tourism was established and the AAA meeting in Mexico City 1974 illustrates the process of interessement at work:

\#37 O/F/S/W/D: ... in $1974 \mathrm{I}$ inserted a notice in the Newsletter of the American Anthropological Association, which asked in essence, "Is anyone else interested in the study of tourism?" ... [This led to the AAA Meeting in Mexico City 1974 where] ...everyone seemed to feel that we, in one day, had opened the door to a new field of research with vast implications. The spirit of innovation, almost magical in form, filled the air (Nash, 2007, p. $185)$.

One informant describes this as:

\#31 O/M/S/W/D: Valene Smith's epic AAA meeting (Nash, 2007, p. 103).

Through this meeting it can be seen how informant \#37 becomes a primary actor, and point of translation:

\#32 O/M/S/NW/D: [Valene Smith] ... has done the most to introduce the social sciences and tourism to one another. Much of the multidisciplinary strength in tourism research we witness today is due to her pathmaking initiatives (Nash, 2007, p. 117).

Furthermore a number of academics were enrolled into this network and the business of translation got underway as people and things that were working and being worked upon in different disciplines began to converge in an emerging field:

\#37 O/F/S/W/D: When I made the announcement of the Symposium, I found that there were 28 fellow anthropologists, as well as geographers, sociologists, and economists who agreed that it was time to talk tourism! (Nash, 2007, p. 192).

\#37 O/F/S/W/D: We soon learned also that Charles Goeldner had started the Journal of Travel Research, Jafar Jafari was pioneering Annals of Tourism Research and Tej Vir Singh was preparing to launch Tourism Recreation Research. Together, we had taken important steps in founding a field (Nash, 2007, p. 192).

Mexico City turns out to have been a popular place for network formation and a starting point for the eventual establishment of RC-50, the specialist tourism committee of the International Sociological Association:

\#30 O/M/S/W/D: ... I joined and attended [a] session [of the International Sociological Association (ISA)] in Mexico City and soon discovered a couple of kindred spirits, notably Marie-Françoise Lanfant and Kryzstztof Przeclawski; and before long we began plotting the creation of a separate tourism unit within the ISA (Nash, 2007, p. 81).

And whilst network formation around the social science of tourism was occurring in the USA a similar process of problematisation, interessement and enrolment around the business of tourism was developing in the UK:

\#57 O/M/S/W/D: [Rik Medlik] then spent the next decade ... consolidating the position of hospitality and tourism studies. This included the production of further books and scholarly papers; the initiation of two scholarly journals, the short lived HCIMA Review and the longlived Tourism Management; ... leadership of the group that set up the first professional body, the Tourism Society, now in its 30th year; and sitting on and chairing numerous government and other committees (Airey, 2007, p. 1382).

Medlik is identified as another primary actor:

\#57 O/M/S/W/D: In many respects he was the creator of tourism and hospitality studies. He staked out the territory, he championed its importance and he provided its initial credibility (Airey, 2007, p. 1381).

This network formation and consolidation performed an important role in advancing this new field in the face of other hostile networks. So for example Medlik's extensive enrolment of allies into the business of tourism network meant that he was able to develop: 
\#57 O/M/S/W/D: ... the first [UK] degree programme in Hotel and Catering Administration [University of Surrey] in $1966 \ldots$ in the face of scepticism and hostility from a very traditional academic community (Airey, 2007, p. 1381).

Similarly a burgeoning network was able to support Annals against hostile critique: $\# 32$ O/M/S/NW/D: ... the advocacy-oriented players of the time did not receive [the Annals] journal sympathetically. But critical voices were gaining momentum and Annals started receiving increasing attention within a small, mostly academic circle (Nash, 2007, p. 113).

And a continuing process of interessement is exemplified by the enrolment of: \#32 O/M/S/NW/D: ... Eduardo Fayos-Sola who has now managed to firmly lodge tourism research and education in the structure of the World Tourism Organization (Nash, 2007, p. 118).

In ANT terms both Smith and Medlik were offering new translations. For example Smith was making the case that anthropology, geography, sociology, and economics could be gathered and translated into a tourism perspective.

More recently, the critical tourism network is an example of a network under formation. It demonstrates many of the classic ANT phases and the coming together of many disparate entities "which then by dint of hard labour, good rhetoric, propitious social and academic contexts and useful machines and devices produce provisionally commensurate connections" (Barnes, 2001, p. 531). So, for example, a number of articles (Hollinshead, 1991; Tribe, 2001; Jamal \& Everett, 2004; Higgins-Desbiolles, 2005) had introduced aspects of critical theory to tourism but a conference in Dubrovnik in 2005 brought together some of these and other entities that had previously been disparate and unconnected. Reflecting on the Dubrovnik conference informant 44 saw its potential network power:

\#44 Y/F/J/W/D: Although we can find niches of support, networks and friends, could a subdiscipline [critical tourism studies] that not only builds on ... such supportive networks but comes from them, such that they are integral to its progression, offer some alternative ontologies and epistemologies? (Ateljevic et al., 2007, p. 394).

Hard labour by a group of enthusiasts meant that Dubrovnik 2005 was followed by Split 2007 where an atmosphere of dialogue and mutual support was evident:

\#54 Y/F/J/NW/D: My faith in tourism conferences was ... renewed after attending last year's (2007) conference in Spilt, Croatia. In all honesty I received more support there than ever before in my tourism career.

\#12 Y/F/J/W/D: we're just enjoying the buzz of being the second generation of tourism scholars.

But networks are all potentially precarious and relations need to be repeatedly 'performed' for networks to be maintained. For the critical network, Split was followed by Zadar 2009 and the "critical turn" has been inscribed in a durable "immutable mobile" in the form of a book (Ateljevic et al., 2007) as well journal special editions.

\section{Inscriptions}

Barnes (2001) explains the importance of books as mobile inscriptions and how they forge connections and extend networks. They are "immutable mobiles" (Latour, 1987) that is to say their message does not get corrupted as it travels and are therefore efficient in transmitting the message "in order to make more allies - the name of the game in ANT" (Barnes, 2001, p. 528). As an example of their power Barnes (2001, p. 540) explains how certain books "... became an active component in the very invention and maintenance of ... a discipline". For tourism it is possible to discern key inscriptions that 
both embody and continue to perform the field. For example on the business side informants point to:

\#57 O/M/S/W/D: ... the highly influential textbook Tourism: Past, present and future (Burkart \& Medlik, 1974) (Airey, 2007, p. 1381-82).

\#49 O/M/S/W/D: ... the first edition of the Cooper, Gilbert, Fletcher \& Wanhill.

Whilst on the social science side the following are cited:

\#24 O/M/J/NW/LD: Hosts and Guests: The Anthropology of Tourism

\#56 O/F/S/W/D The Tourist (MacCannell); The Tourist Gaze (Urry)

\#29 O/M/S/W/D The Golden Hordes (Turner and Ash) ... (Nash, 2007, p. 67)

\#26 Y/F/J/NW/D: Cohen (1974, 1979).

Additionally, encyclopaedias by their very name press very hard to define a field and impose authoritative readings:

\#24 O/M/J/NW/LD: Jafar Jafari's edited 'Encyclopaedia of Tourism'.

One informant underlines the solidity of key immutable mobiles

\#8 O/M/S/W/D: there's a few solid pieces of work and they're still standing there as kind of brutal obstacles to our future progress.

Diagrams too represent powerful inscriptions. Haraway (1996, p. 135) talks of "fetishism in the form of maps and figures" and one respondent explains how Leiper's (1990) systems model both describes and defines tourism studies:

\#64 O/F/J/W/D: Six of ... nine major textbooks use Leiper's systems theory approach as their basic paradigm in which the content and structure is grounded. This illustrates the high degree to which Leiper's theory is, tacitly or otherwise, disseminated among students of tourism and hospitality...

Annals, Tourism Management and the Journal of Travel Research are consistently cited by informants as the key journals of the field triangulating with the findings of McKercher, Law and Lam (2006). They are key inscription devices whose "immutability and mobility allow for their geographical diffusion, permitting connections to be forged between quite different and geographically separated local communities." (Barnes, 2002, p. 493). Indeed journals are a way in which network space can be easily compressed and crumpled and networks overcome apparent barriers of geographical distance.

However Barnes (2001, p. 532) also describes how books offer points of novel translation which "once published and in circulation [are a] means to gather new allies, whether they be students, university academic boards, or politicians. [They] became a point of passage, offering the possibility of translations, of drawing together entities that formerly seemed irreconcilable". So just as the above books provided some of the early network translations later books spawned new network spaces. For example:

\#49 O/M/S/W/D: Poon's (1993) text was a landmark, especially the parts on old and new tourism. ... The Holidaymakers' was a ground breaking text - it was also good to read!

\#61 Y/F/J/NW/D: I see landmarks in tourism as those elements that pushed tourism away from its economic-focused existence. Thus, Britton's (1991) call for a more critical tourism research agenda, de Kadt's 'Passport to Development', Urry's tourist gaze 1990, MacCannell's 'Tourist', the critical and cultural turns, Butler's Life Cycle, new mobilities paradigm, first critical tourism conference in Croatia, first research body grants given where 'tourism' was the focus of the proposed projects (recognition in field), the birth of Tourist Studies journal ...

\section{Obligatory Passage Points}


ANT speaks of the importance of obligatory passage points (Latour, 1987) where "anyone wanting to do anything in the discipline needs to make some reference to such points if they are both to be taken seriously, and to do the things that they claim to do" (Barnes, 2002, p. 494). Discussion of "gatekeepers" covered this point and informants 20 and 21 identify some of these obligatory passage points and question their influence of equality of access:

\#20 Y/F/J/NW/D: ... editor-in-chief and the editorial board of a journal publication and recruitment panel for academic positions in higher education. Whether there is equality of access through these gates remains debatable.

\#61 Y/F/J/NW/D: ... journals and access to knowledge being guarded by white, middle class men in general.

Informant 16 talks of the physical manifestation of obligatory passage points with academics "hanging around" these important figures:

$\# 16$ O/M/S/W/D: I've seen the power groupies ... You see at all these places people who are perceived to have power and influence and a range of people hang around them because of that ...

Gatekeepers appear less important for established researchers but may block the paths of younger or "third world" academics:

IV: Do you find yourself coming up against gate keepers in a negative way?

\#2 O/F/S/W/D: No, I don't ... I might have when I was younger and at a lower position.

\#6 Y/F/J/NW/D Sometimes I think as a new researcher, even though I know journals are all peer reviewed, it's quite difficult to get into that.

\#24 O/M/J/NW/LD: There is a lot of urging and arguing that academics should not be dominated by Western thought and that articles from third world countries should be encouraged. But there is a bias in the minds of many editors of journals ... So the answer is no, there is little equality of access.

Two informants explain how key journals constitute obligatory passage points and how these therefore guide regimes of truth and establish dominant discourses (Foucault, 1971) in the field:

\#20 Y/F/J/NW/D: ... the two most prestigious journals for disseminating the findings of tourism research continue to be the pioneers: Annals of Tourism Research and Journal of Travel Research ... Yet the fact remains that not all that claims to be tourism research finds acceptability within these journals. ... It means the defined limits of what can and what cannot be published in these journals constitute the regimes of truth through which tourism research is directly or indirectly governed. You either operate within these defined discourses and be in with a chance of getting published or perish.

\#16 O/M/S/W/D ... JTR and Annals ... had a very traditional academic board who were looking at things in a particular way ... if you've got something that challenges the norm, then it's unlikely to get through the process ...

But the following explains how Annals challenged the conventional industry and quantitative obligatory passage points therefore extending the range of what could pass: \#32 O/M/S/NW/D: I added the subtitle "A Social Sciences Journal" [to Annals]. With an obvious tendency to favor research for the sake of research, with or without immediate applications in the industry, Annals parted ways from the mainstreams of the time. ... The then-favored quantitative research methods that were often used in economic contributions to tourism research began to give way in Annals to the qualitative treatment of the subject as a sociocultural phenomenon (Nash, 2007, p. 113-114).

Informant 8 argues that tourism gatekeepers are less stringent than in some other disciplines: 
\#8 O/M/S/W/D: I grew up inside of a very, very fusty old Sociology and Anthropology establishment ... and there was definitely a sense, you play the game according to their rules and then if you do, you're lucky if they let you in. I don't see that happening for the very reason that Tourism is much more diffuse and it doesn't have the kind of monolithic structure that 1950 s and 60 s social sciences had.

Finally, whilst taken for granted by Anglophone researchers the English language operates a difficult obligatory passage point for many researchers:

\#11 Y/M/J/W/LD: I think in the academy we forget about the people in marginal areas, like people ... that don't work with English ... I think there is a group that don't have access.

\section{Conclusions}

The conclusions fall into two major headings of new ways of understanding and a review of findings. Under the first heading this article applied the Becher and Trowler model to tourism studies. It enriched their analysis by invoking concepts such as postdisciplinarity, ideology, discourse, surveillance, traditions, performativity and invisible colleges. It additionally utilised actor network theory to integrate the previously separate epistemological and sociological approaches and better understand the power dynamics of tourism knowledge creation. Here it supports the views of Barnes (2001, p. 528-529) who noted that "holding a network together is power" and of van der Duim (2007, p. 966) who argues that "an appropriate point of departure for an analysis of power would be not agency but the social relations that constitute effective agency" (i.e. the relations that are surfaced by actor network theory). This article has demonstrated how effective agency in the form of creating traditions of knowledge and indeed resisting and modifying these traditions results from configuration and performance of effective sociotechnical networks.

The review of findings is divided into the three categories of territories, tribes and networks. The territory of tourism studies is viewed not as a discipline but rather a fragmented field of study supporting Tribe's (1997) indiscipline thesis. It remains a largely multidisciplinary endeavor with little reported use of post-disciplinarity, or even nomadology. Evidence also supports Tribe's portrayal of two major fields but these are more widely understood as The Business of Tourism and Tourism Social Science rather than Tribe's somewhat clumsy TF1 and TF2 fields. However Tribe's contention that The Business of Tourism is overrunning the field is refuted, indeed there is a surprising lack of evidence of applied, extra-disciplinary work. Moreover the social science network remains strong and other networks based around interpretative methods, sustainability and critical theory have established a footing. This eclecticism is possible because tourism studies is not governed by a paradigm. Rather it is a soft, permeable field able to support different traditions which can coexist and which are susceptible to new schools of thought. However some point to the overarching paradigm of neo-liberalism disciplining how the subject operates. The territorial map provided by the tourism canon reveals what Becher and Trowler (2001) refer to as a rural field. That is one with an extensive range of themes and space for variety and cooperation rather than a highly competitive urban specialism focused on a limited number of central topics. The canon contains distinctive, key inscriptions and includes a collection of concepts and theories that have in the main been adapted from their origins in contributory disciplines demonstrating the process of finitism. 
Analysis of tourism tribes reveals that the tourism academic community is not a convergent one governed by " 'reasonably uniform standards ... 'intellectual control' and a 'stable elite" " (Becher \& Trowler, 2001, p. 185) and points rather to a divergent community which allows a broad range of approaches and tolerates individual difference. It is interesting to note here a congruence between tribes (no convergent community) and territories (no paradigm). Within this divergent community there are references to dominant clans in terms of gender, age and ethnicity (as well as resistance to this) and there is also evidence of tribal allegiance to, and some rivalry between, those in different clans (e.g. business vs. social science). It is also true that universities and departmentalism sometimes forge convergence and there are other converging influences, for example elders and gatekeepers, a well established invisible college, funding regimes and key journals which define and promote significant obligatory passage points. Individual research freedom can also be constrained by performativity yet divergence is maintained through cheap and hobby research. Research freedom also appears easier to claim by older researchers holding senior positions. Other evidence of divergence includes the gradual rise of a new guard with more gender balance and the Academy of Tourism facing competition for influence from other networks groupings.

Network analysis has shown how two exemplar tourism studies networks have been developed and performed, how new networks are coming into being and underlined the importance of material and non-material influences. Tourism Studies could have taken many different forms but after Latour (1987) it developed from 'unconnected localities' and worked up 'provisionally commensurable connections'. It went from atomised, disparate knowledge through a period of institutionalisation as illustrated by the formation of the two deep networks of tourism social science and the business of tourism. But other networks are evident. Some resistance to the business of tourism sparked research in other 'unconnected localities' in sustainable tourism. More recently critical tourism is enrolling, people, ideas and inscriptions. Other networks such as ATLAS, ISARC50, TTRA, APTA and CAUTHE hold together actors by region or special interest. In contrast whilst the mobilities paradigm has enrolled scholars, journals and books it has not successfully recruited mainstream tourism studies allies and it remains a network largely outside of tourism with only small network overlap.

These concluding remarks present a macro picture of the field of tourism driven by dynamic networks and exhibiting strengths in its sweep of remit and openness to new ideas. Paradoxically the data also reveals that at the micro level of the individual some feel marginalised and limited in their freedom to research. It also highlights tensions between industry vs. blue skies research, individuals vs. institutions, new guard vs. old guard, business vs. social science and those who feel outsiders vs. insiders. Further there is some frustration at the bottlenecking and standardising caused by the operation of obligatory passage points. There is also evidence of omissions in the canon so that "other" knowledges, extra-metropolitan research, under-empowered groups and valuesbased research are overlooked. Additionally there is some shakiness in the foundations of tourism studies in terms of lack of own theory which also manifests itself in the uncertain skills of generation $\mathrm{T}$. 
But the analysis of this article also suggests ways that issues of research silences, tensions, invisibilities, marginalised individuals and inequality of opportunity might be overcome. This would be by enrolling people and things to create strong networks of relations to unleash effective agency in these areas. This in turn would generate feelings of empowerment and solidarity.

\section{References}

Airey, D. (2005). Growth and development. In D. Airey and J. Tribe (Eds.), An international handbook of tourism education (pp. 13-24). Oxford: Elsevier.

Airey, D. (2007). Professor Rik Medlik 1928-2007. Tourism Management, 28, 13811382.

Aronowitz, S. \& Giroux, H. (1991). Postmodern education: politics, culture, and social criticism. Minneapolis: University of Minnesota Press.

Ateljevic, I., Harris, C., Wilson, E., \& Collins, F. L. (2005). Getting 'entangled': reflexivity and the 'critical turn' in tourism studies. Tourism Recreation Research, 30, 9-21.

Ateljevic, I., Pritchard, A., \& Morgan, N. (2007). The critical turn in tourism studies: Innovative research methods. Oxford: Elsevier.

Barnes, T. J. (2001). 'In the beginning was economic geography' - a science studies approach to disciplinary history. Progress in Human Geography, 25, 521.

Barnes, T. J. (2002). Performing economic geography: two men, two books, and a cast of thousands. Environment and Planning A, 34, 487-512.

Becher, T. \& Trowler, P. (2001). Academic tribes and territories. (2 ed.) Buckingham: Open University Press.

Biglan, A. (1973). The characteristics of subject matter in different academic areas. Journal of Applied Psychology, 57, 195-203.

Botterill, D. (2003). An autoethnographic narrative on tourism research epistemologies. Loisir et Societé, 26(1), 97-110.

Callon, M. (1980). Struggles and negotiations to define what is problematic and what is not: the socio-logic of translation. The Social Process of Scientific Investigation, 4, 197-219.

Callon, M. (1991). Techno-economic network and irreversibility. In J. Law (Ed.), A sociology of monsters. Essays on power, technology and domination (pp. 132164). London: Routledge.

Callon, M. (2001). Actor network theory. In J. S. Neil \& B. B. Paul (Eds.), International encyclopedia of the social and behavioral sciences (pp. 62-66). Oxford: Pergamon.

Creswell, J. (1998). Qualitative inquiry and research design. Choosing among five traditions. Thousand Oaks, CA: Sage Publications.

Coles, T., Hall, C. M., \& Duval, D. (2005). Post-disciplinary tourism. In J. Tribe (Ed.), Philosophical issues in tourism (pp. 80-100). Bristol: Channel View.

Crane, D. (1972). Invisible colleges: Diffusion of knowledge in scientific communities. Chicago: University of Chicago Press. 
Deleuze, G. and Guattari, F. (1988). A thousand plateaus. London: The Athlone Press. Foucault, M. (1971). L'ordre du Discours. Paris: Gallimard.

Foucault, M. (1980). Power / knowledge; selected interviews and other writings 1972-77. Brighton: Harvester Press.

Gibbons, M., Limoges, C., Nowotny, H., Schwartzman, S., Scott, P., \& Trow, M. (1994). The new production of knowledge. London: Sage.

Hall, M. (2004). Reflexivity and tourism research: situating myself and/with others. In J. Phillimore \& L. Goodson (Eds.), Qualitative research in tourism: Ontologies, epistemologies and methodologies (pp. 137-155). London: Routledge.

Hannam, K. (2009). The end of tourism? Nomadology and the mobilities paradigm. In J. Tribe (Ed.), Philosophical issues in tourism (pp. 55-70). Clevedon: Channel View.

Haraway, D. J. (1991). Simians, cyborgs, and women: The re-invention of nature. London: Routledge.

Haraway, D. J. (1996). Modest witness @ second millenium. Femaleman meets oncomouse. New York: Routledge.

Higgins-Desbiolles, F. (2005). Encounters between the wretched of the earth and the tourist. Hong Kong: Ecumenical Coalition on Tourism.

Hollinshead, K. (1991). 'White' gaze, 'red' people - shadow visions: the disidentification of 'Indians' in cultural tourism. Leisure Studies, 11, 43-64.

Jamal, T. B. \& Everett, J. (2004). Resisting rationalisation in the natural and academic life-world: critical tourism research or hermeneutic charity? Current Issues in Tourism, 7, 1-19.

Kuhn, T. (1962). The structure of scientific revolutions. Chicago: University of Chicago Press.

Latour, B. (1987). Science in action; How to follow scientists and engineers around society. Cambridge, MA: Harvard University Press.

Latour, B. (2005). Reassembling the social: An introduction to Actor-Network-Theory. New York: Oxford University Press.

Law, J. (1992). Notes on the theory of the actor-network: ordering, strategy, and heterogeneity. Systems Practise, 5, 379-393.

Law, J. (1999). After ANT: complexity, naming and topology. In J. Law \& J. Hassard (Eds.), Actor network theory and after (pp. 1-14). Oxford: Blackwell.

Leiper, N. (1990). Tourism systems: An interdisciplinary perspective. (Occasional Paper \#1). New Zealand: Department of Management Systems, Massey University.

Lyotard, J. (1984). The postmodern condition: A report on knowledge. Manchester: Manchester University Press.

MacIntyre, A. (1985). After virtue: A study in moral theory. London: Duckworth.

McKercher, B. (2008). A citation analysis of tourism scholars. Tourism Management, 29, 1226-1232.

McKercher, B., Law, R., \& Lam, T. (2006). Rating tourism and hospitality journals.

Tourism Management, 27, 1235-1252.

Merton, R. K. (1973). The sociology of science. Chicago: University of Chicago Press.

Nash, D. (2007). The study of tourism: Anthropological and sociological beginnings. Oxford: Elsevier. 
Pearce, P. L. (2005). Australian tourism education: The quest for status. Journal of Teaching in Travel \& Tourism, 5, 251-267.

Rae, W. (1891). The business of travel. London: Thomas Cook and Son.

Swain, M. \& Hall, D. (2007). Gender analysis in tourism: Personal and global dialectics. In I. Ateljevic, A. Pritchard, \& N. Morgan (Eds.), The critical turn in tourism studies: Innovative research methodologies (pp. 91-104). Oxford: Elsevier.

Tribe, J. (1997). The indiscipline of tourism. Annals of Tourism Research, 24, 638-657.

Tribe, J. (2001). Research paradigms and the tourism curriculum. Journal of Travel Research, 39, 442.

Tribe, J. (2006). The truth about tourism. Annals of Tourism Research, 33, 360-381. van der Duim, R. (2007). Tourismscapes an actor-network perspective. Annals of Tourism Research, 34, 961-976. 